\title{
Evidence of Altered Glycosylation of Serum Proteins Prior to Pancreatic Cancer Diagnosis
}

\author{
Shibu Krishnan ${ }^{1}$, Harry J. Whitwell ${ }^{2}$, Joy Cuenco ${ }^{2}$, Aleksandra Gentry-Maharaj ${ }^{2}$, \\ Usha Menon ${ }^{2}$, Stephen P. Pereira ${ }^{3}$ (D), Marco Gaspari ${ }^{1}$ and John F. Timms ${ }^{2, *}$ \\ 1 Research Center for Advanced Biochemistry and Molecular Biology, Department of Experimental \\ and Clinical Medicine, University of Catanzaro 'Magna Graecia', 88100 Catanzaro, Italy; \\ shibu.krishnan@farmaci.uu.se (S.K.); marco.gaspari1@gmail.com (M.G.) \\ 2 Institute for Women's Health, University College London, Gower Street, London WC1E 6BT, UK; \\ h.whitwell@imperial.ac.uk (H.J.W.); joy.cuenco@gmail.com (J.C.); a.gentry-maharaj@ucl.ac.uk (A.G.-M.); \\ u.menon@ucl.ac.uk (U.M.) \\ 3 Institute for Liver and Digestive Health, Royal Free Hospital Campus, University College London, \\ London NW3 2QG, UK; stephen.pereira@ucl.ac.uk \\ * Correspondence: john.timms@ucl.ac.uk; Tel.: +44-207-679-6598
}

Received: 13 November 2017; Accepted: 6 December 2017; Published: 9 December 2017

\begin{abstract}
Biomarkers for the early detection of pancreatic cancer are urgently needed. The aim of this pilot study was to evaluate changes in serum $\mathrm{N}$-glycoproteins and their glycosylation status prior to clinical presentation of pancreatic cancer that may be potential biomarkers. Prediagnosis serum samples pooled according to five time-to-diagnosis groups and a non-cancer control pool were digested with trypsin, labelled with mass tags, and subjected to titanium dioxide capture, deglycosylation, and 2D-LC-MS/MS profiling. Unbound peptides were profiled in parallel. Across the sample groups, 703 proteins were quantified and 426 putative sites of $\mathrm{N}$-glycosylation were identified with evidence of several novel sites. Altered proteins with biomarker potential were predominantly abundant inflammatory response, coagulation, and immune-related proteins. Whilst glycopeptide profiles largely paralleled those of their parent proteins, there was evidence of altered $\mathrm{N}$-glycosylation site occupancy or sialic acid content prior to diagnosis for some proteins, most notably of immunoglobulin gamma chains. $\alpha$-1-Antitrypsin was tested as a biomarker, but found not to complement carbohydrate antigen 19-9 (CA19-9) in early detection of cancer. In conclusion, we provide preliminary evidence of altered glycosylation of several serum proteins prior to pancreatic cancer diagnosis, warranting further investigation of these proteins as early biomarkers. These changes may be largely driven by inflammatory processes that occur in response to tumour formation and progression.
\end{abstract}

Keywords: pancreatic cancer; biomarkers; $N$-glycosylation; serum; titanium dioxide; UKCTOCS

\section{Introduction}

Pancreatic ductal adenocarcinoma (PDAC) is a leading cause of cancer death and has the lowest five year survival rate for any solid tumour $(3-6 \%)[1,2]$. It is clear that early detection of smaller tumours is necessary to improve resectability rates and survival. The serum marker carbohydrate antigen 19-9 (CA19-9) [3-5] is the only biomarker used routinely in the management of PDAC for monitoring treatment response. For diagnosis, it has a $79-81 \%$ sensitivity and $82-90 \%$ specificity [6], although is often elevated in benign pancreatobiliary diseases such as obstructive jaundice, pancreatitis, and cholangitis [7-9]. Moreover, $8-10 \%$ of the Caucasian population with the Lewis $a-b-$ genotype do not express CA19-9; these individuals lack the FUT2 and FUT3 fucosyltransferases, and fail to generate the CA19-9 epitope which is the sialylated Lewis A blood group antigen $[8,10]$. For these reasons, 
serum CA19-9 is not recommended for diagnosis of PDAC. Several studies have also concluded that CA19-9 testing alone has no utility as a screening tool for PDAC [11-13], although we recently showed its elevation up to 3 years before diagnosis in some individuals, indicating its potential as a first line screening test for early detection [14]. Other reported non-invasive diagnostic and/or prognostic markers of PDAC that have been tested alone or in combination include CA125 [14-18], CEA [19], CEACAM1 [20], MUC1 [21], OPN/SPP1 [22], MIC1/GDF15 [23], REG3A/PAP1 [24,25], and PKM2 [26]. As yet, the clinical utility of most reported markers has yet to be determined and requires multicenter validation.

The modification of membrane and secreted proteins by $O$ - and $N$-linked glycosylation is a widespread co- and post-translational modification, with glycans serving a variety of structural and functional roles, including protein folding and stability and involvement in cell adhesion and immune responses [27]. Accumulating evidence shows that glycan structures are frequently altered in cancer, including PDAC [28-32], and may contribute to the etiology of the disease through changes in cellular adhesion, membrane trafficking, endogenous lectin binding, inflammation, immune function, and metastasis [31,33,34]. An increase in the size of tumour cell-derived $N$-glycans has been explained by increased $\beta 1-6$ branching due to aberrant expression of the MGAT5 glycosyltransferase, with concomitant increase in galactose, fucose, and sialic acid content [33]. Conversely, cancer-associated $O$-glycans are often truncated, highly sialylated, and contain N-acetylgalactosamine (GalNAc) and Galß1-3GalNAc, the so-called Tn and T antigens, with modifications of the mucin family of proteins the most widely studied [35]. Such tumour-specific alterations in glycans make them potential biomarker candidates for use in cancer diagnosis, prognosis, and early detection.

Whilst much effort has gone into profiling glycoproteins and their glycan modifications for biomarker discovery in body fluids, this has yet to yield clinically useful biomarkers. The reasons for this are likely due to the complexity and heterogeneity of biofluids and glycosylation, poor study design, and the common identification of abundant glycoproteins that lack specificity for detecting cancer. Profiling methods include the use of lectin arrays [36], enrichment with immobilised lectins of differing binding specificities [37], titanium dioxide enrichment of sialylated glycopeptides [38], or periodate oxidation of sugars combined with hydrazide capture [39]. These enrichment methods can be combined with enzymatic release of nonglycosylated peptides using a protease, or the release of captured $\mathrm{N}$-glycosylated peptides using a glycosidase such as PNGaseF (Peptide: $\mathrm{N}$-Glycosidase F); formerly glycosylated peptides are then identified and quantified by liquid chromatography tandem mass spectrometry (LC-MS/MS).

The focus of this pilot study was to examine potential changes in serum glycoprotein levels and/or their glycosylation early in the progression of PDAC. Ideally, biomarker studies addressing early detection of cancer should make use of prediagnosis samples to allow the assessment of early changes and the consistency of those changes in the lead-up to diagnosis. For this reason, serum samples were taken from the biobank of the UK Collaborative Trial of Ovarian Cancer Screening (UKCTOCS); a randomised controlled trial of ovarian cancer assessing impact of screening on mortality [40,41]. Prediagnosis samples from participating women who subsequently developed PDAC and matched noncancer controls were used, applying titanium dioxide enrichment of sialylated glycopeptides with parallel profiling of total proteins and captured glycopeptides across a time course to diagnosis, using quantitative LC-MS/MS based on isobaric mass tagging.

\section{Results}

\subsection{Protein and Glycopeptide Profiling of Serum from Cancer-Free Controls and Cases of Pancreatic Ductal} Adenocarcinoma Taken Months to Years before Diagnosis

The aim of this pilot investigation was to evaluate changes in serum $\mathrm{N}$-glycoproteins and their glycosylation status prior to clinical presentation of PDAC in the search for candidate biomarkers for early detection of the disease. Prediagnosis serum samples sourced from the UKCTOCS were 
pooled according to five time-to-diagnosis groups and a noncancer control pool, and were digested with trypsin, labelled with mass tags, and subjected to titanium dioxide capture, deglycosylation, and 2D-LC-MS/MS profiling. Unbound peptides were profiled in parallel. In total, 852 protein groups were identified from a combined data analysis with a false discovery rate of $2.3 \%$ (Mascot significance threshold $<0.05$; peptide score $\geq 20$ ). Across all six sample groups, 703 proteins were quantified using Tandem Mass Tag (TMT reporter ion intensities (Tables S1 and S2). Of these proteins, 167 were identified as putative $\mathrm{N}$-glycosylated proteins based upon matched peptides containing the consensus $\mathrm{N}$-glycosylation sequence Asn-Xaa-Ser/Thr, where Xaa $\neq$ Pro and Asn is deamidated (Tables S1 and S3). Proteins were scored to give a proxy measure of biomarker potential, with emphasis on data quality and consistent change in the lead-up to diagnosis. The top scoring proteins from this analysis were mostly abundant serum proteins involved in the inflammatory response, coagulation, and immunity, with the top scoring protein, $\alpha-1$-antitrypsin (A1AT), showing a consistent increase in cases versus controls towards diagnosis (Table 1). The top-scoring glycopeptides largely belonged to this same group of proteins (Table 2).

Table 1. Top scoring glycoproteins. The 20 highest-scoring glycoproteins from the analysis are shown with number of unique peptides, number of peptide spectrum matches, score, and ratios of protein expression in cases versus controls for each time group.

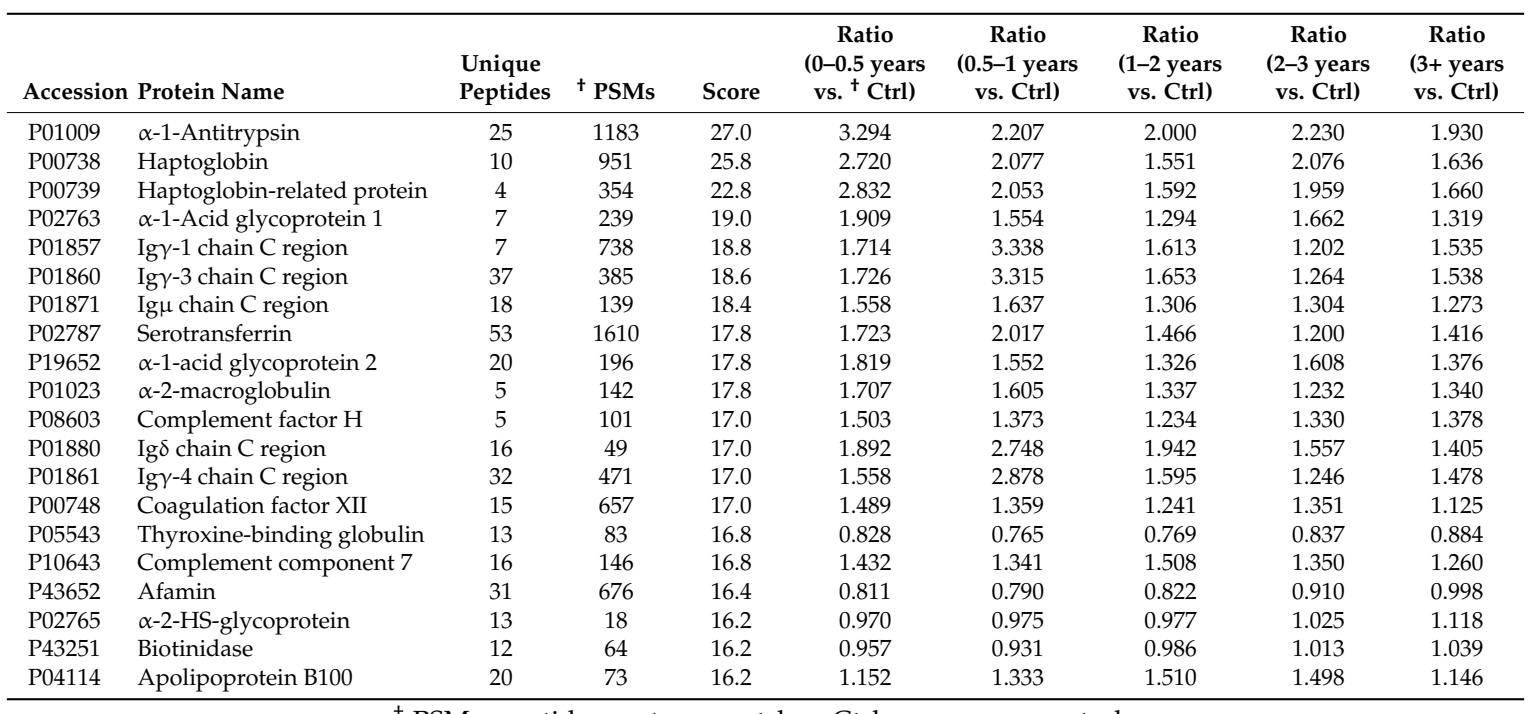

${ }^{\dagger}$ PSMs, peptide spectrum matches; Ctrl, non-cancer control.

Our workflow permitted comparison of glycoprotein and glycopeptide levels for individual proteins, allowing us to evaluate possible changes in $\mathrm{N}$-glycosylation occupancy or sialic acid content in cases versus controls and in the lead-up to diagnosis. Overall, there were no gross differences in global patterns of expression across time groups (Figure 1). Spearman correlation coefficients for glycoproteins versus matched glycopeptides were $0.73,0.77,0.74,0.77$, and 0.66 for the $0-0.5$ years, $0.5-1$ years, $1-2$ years, $2-3$ years, and $3+$ years case-control comparisons, respectively. Indeed, for most of the high-scoring glycoproteins, the pattern of expression of their constituent glycopeptides matched to that of the parent protein, indicating that these changes are dependent upon protein expression and not altered glycosylation. Some examples are shown in Figure 2a. Despite this overall similarity, there were several glycoproteins whose constituent glycopeptide profiles deviated from that of the parent protein (Figure $2 \mathrm{~b}$ ). For interleukin-1 receptor accessory protein, protein Z-dependent protease inhibitor, neural cell adhesion molecule L1-like protein, attractin and complement component C7, matching glycopeptides were elevated in cases versus controls, with increasing ratios observed for the attractin and complement component C7 glycopeptides towards diagnosis. Conversely, glycopeptides from scavenger receptor cysteine-rich protein 1 and multimerin 1 were lower in cases, with decreasing 
ratios towards diagnosis, with little change in the parent proteins. For $\alpha$-2-macroglobulin, protein levels moderately increased in cases towards diagnosis, whereas two of its constituent glycopeptides were lower in cases or essentially equivalent.

Table 2. Top-scoring glycopeptides. The 20 highest-scoring glycopeptides are shown with number of peptide spectrum matches, score, and ratios of expression in cases versus controls for each time group.

\begin{tabular}{|c|c|c|c|c|c|c|c|c|c|}
\hline Sequence & Accession & Protein Name & ${ }^{+}$PSMs & Score & $\begin{array}{c}\text { Ratio } \\
\text { (0-0.5 years } \\
\text { vs. Ctrl) }\end{array}$ & $\begin{array}{c}\text { Ratio } \\
\text { (0.5-1 years } \\
\text { vs. Ctrl) }\end{array}$ & $\begin{array}{c}\text { Ratio } \\
\text { (1-2 years } \\
\text { vs. Ctrl) }\end{array}$ & $\begin{array}{c}\text { Ratio } \\
\text { (2-3 years } \\
\text { vs. Ctrl) }\end{array}$ & $\begin{array}{c}\text { Ratio } \\
\text { (3+ years } \\
\text { vs. Ctrl) }\end{array}$ \\
\hline yLGnATAIFFLPDEGk & P01009 & $\alpha-1$-Antitrypsin & 27 & 31 & 4.06 & 2.69 & 2.39 & 2.63 & 2.53 \\
\hline nLFLnHSEnATAk & P00738 & Haptoglobin & 43 & 24 & 2.66 & 1.90 & 1.58 & 1.91 & 1.55 \\
\hline vVLHPnYSQVDIGLIk & P00738 & Haptoglobin & 16 & 20.2 & 2.60 & 1.84 & 1.31 & 1.92 & 1.44 \\
\hline eEqFnSTFR & P01859 & $\operatorname{Ig} \gamma-2$ chain $C$ region & 16 & 19.6 & 0.46 & 0.50 & 0.53 & 0.60 & 0.58 \\
\hline 1GAcnDTLQQLmEVFk & P01008 & Antithrombin-III & 7 & 19 & 0.81 & 0.70 & 0.71 & 0.73 & 0.75 \\
\hline enGTISR & P02763 & $\alpha-1$-Acid glycoprotein 1 & 57 & 19 & 2.25 & 1.74 & 1.48 & 1.99 & 1.45 \\
\hline qDqcIYnTTYLNVQR & P02763 & $\alpha$-1-Acid glycoprotein 1 & 149 & 18.6 & 1.98 & 1.61 & 1.36 & 1.72 & 1.33 \\
\hline $\begin{array}{l}\text { 1GHcPDPVLVnGEFSSSG } \\
\text { PVnVSDk }\end{array}$ & P20851 & C4b-binding protein $\beta$ chain & 8 & 18.4 & 1.66 & 1.76 & 1.37 & 1.55 & 1.44 \\
\hline qNQcFYnSSYLNVQR & P19652 & $\alpha$-1-Acid glycoprotein 2 & 24 & 18 & 1.93 & 1.57 & 1.20 & 1.53 & 1.26 \\
\hline aAIPSALDTnSSk & Q08380 & Galectin-3-binding protein & 24 & 17.6 & 0.90 & 0.94 & 0.99 & 1.00 & 1.09 \\
\hline enGTVSR & P19652 & $\alpha-1-$ Acid glycoprotein 2 & 22 & 17.2 & 1.93 & 1.64 & 1.33 & 1.67 & 1.45 \\
\hline $\begin{array}{l}\text { aDGTVNQIEGEATPVnL } \\
\text { TEPAk }\end{array}$ & P05090 & Apolipoprotein D & 66 & 16.8 & 1.24 & 1.15 & 1.12 & 1.00 & 1.18 \\
\hline $\begin{array}{l}\text { enLTAPGSDSAVFFEQG } \\
\text { TTR }\end{array}$ & P00450 & Ceruloplasmin & 131 & 16.8 & 0.88 & 0.85 & 0.85 & 0.89 & 0.98 \\
\hline nVTAEQAR & P00748 & Coagulation factor XII & 10 & 16.8 & 1.67 & 1.64 & 1.31 & 1.49 & 1.16 \\
\hline
\end{tabular}

${ }^{\dagger}$ PSMs, peptide spectrum matches; Ctrl, non-cancer control.

\section{0-0.5 years vs. Ctrl}

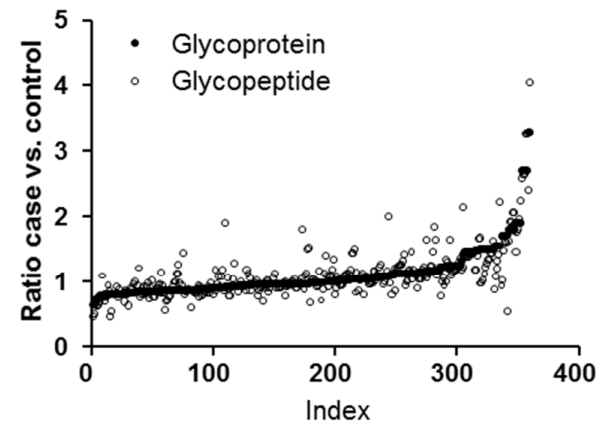

1-2 years vs. Ctrl

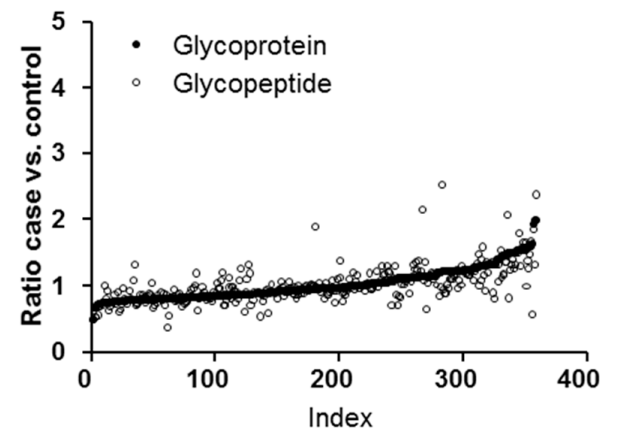

\section{5-1 years vs. Ctrl}

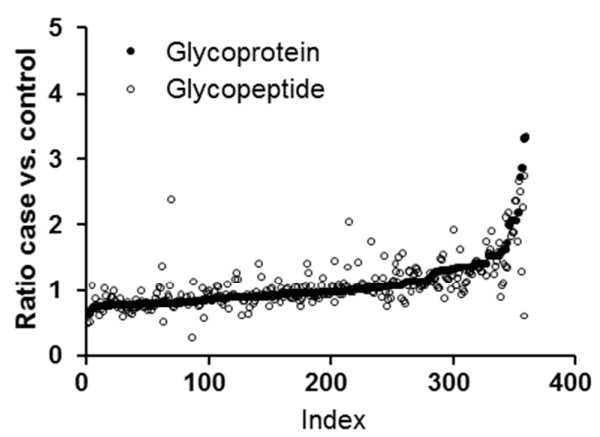

2-3 years vs. CtrI

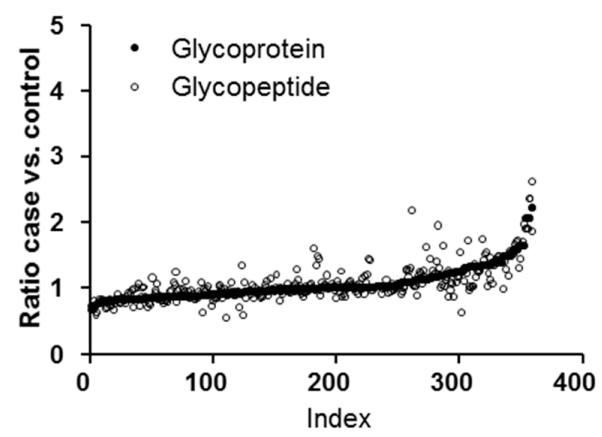

Figure 1. Cont. 
$3+$ years vs. Ctrl

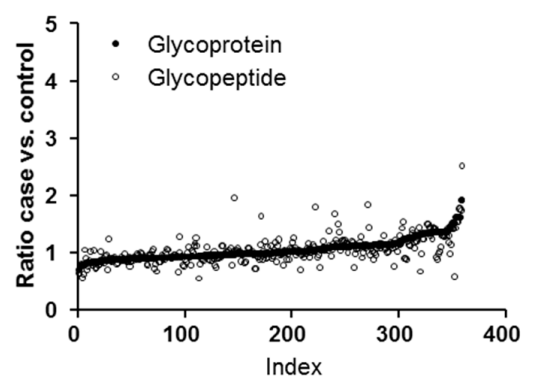

Figure 1. Global comparison of glycoprotein and matched glycopeptide profiles across the time groups. Case versus control (Ctrl) ratios for glycoproteins were indexed in order of increasing ratio for each prediagnosis time group and plotted with ratios of matching glycopeptides. Protein ratios are repeated for proteins with multiple matched glycopeptides.
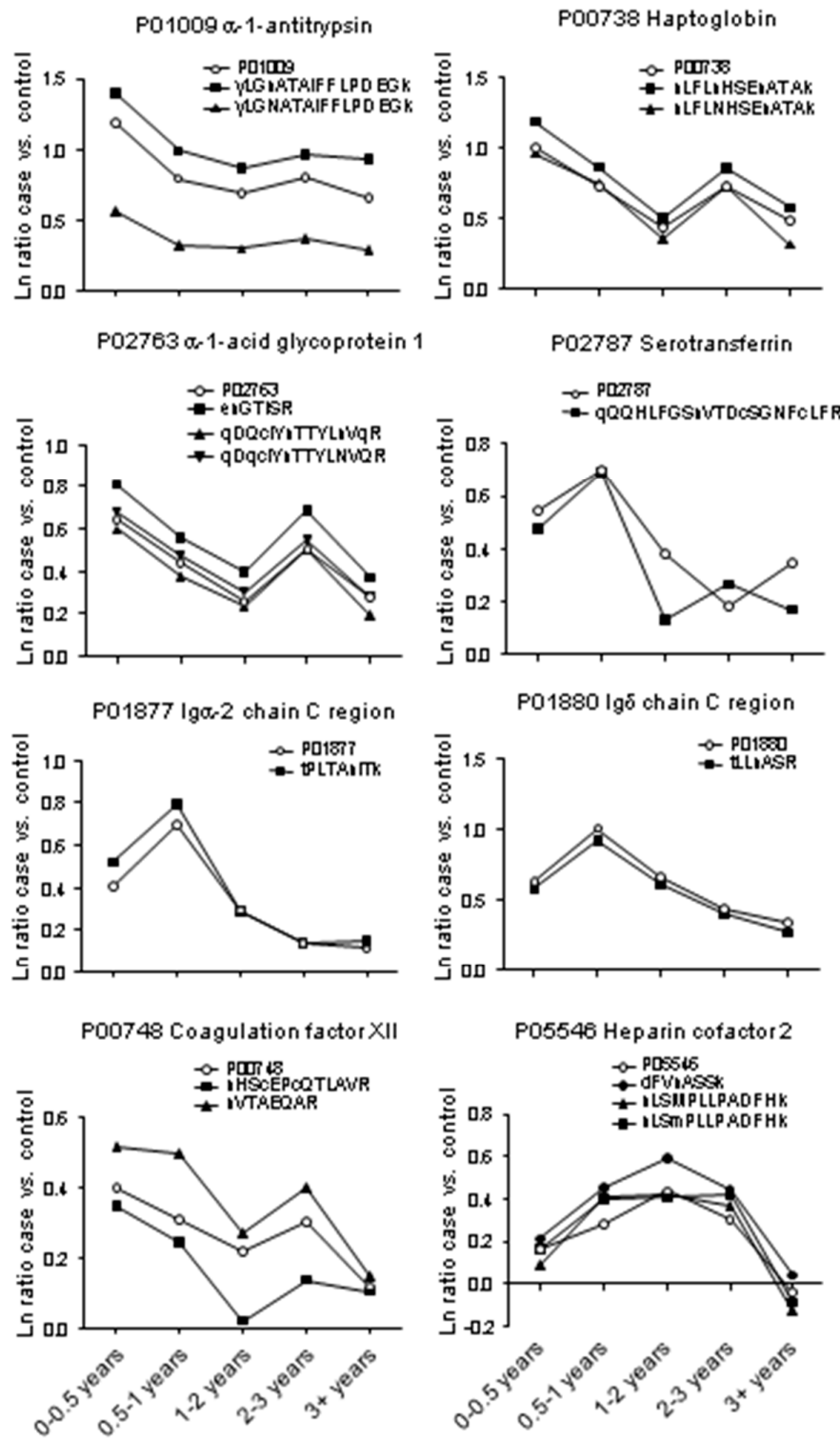

(a)

Figure 2. Cont. 

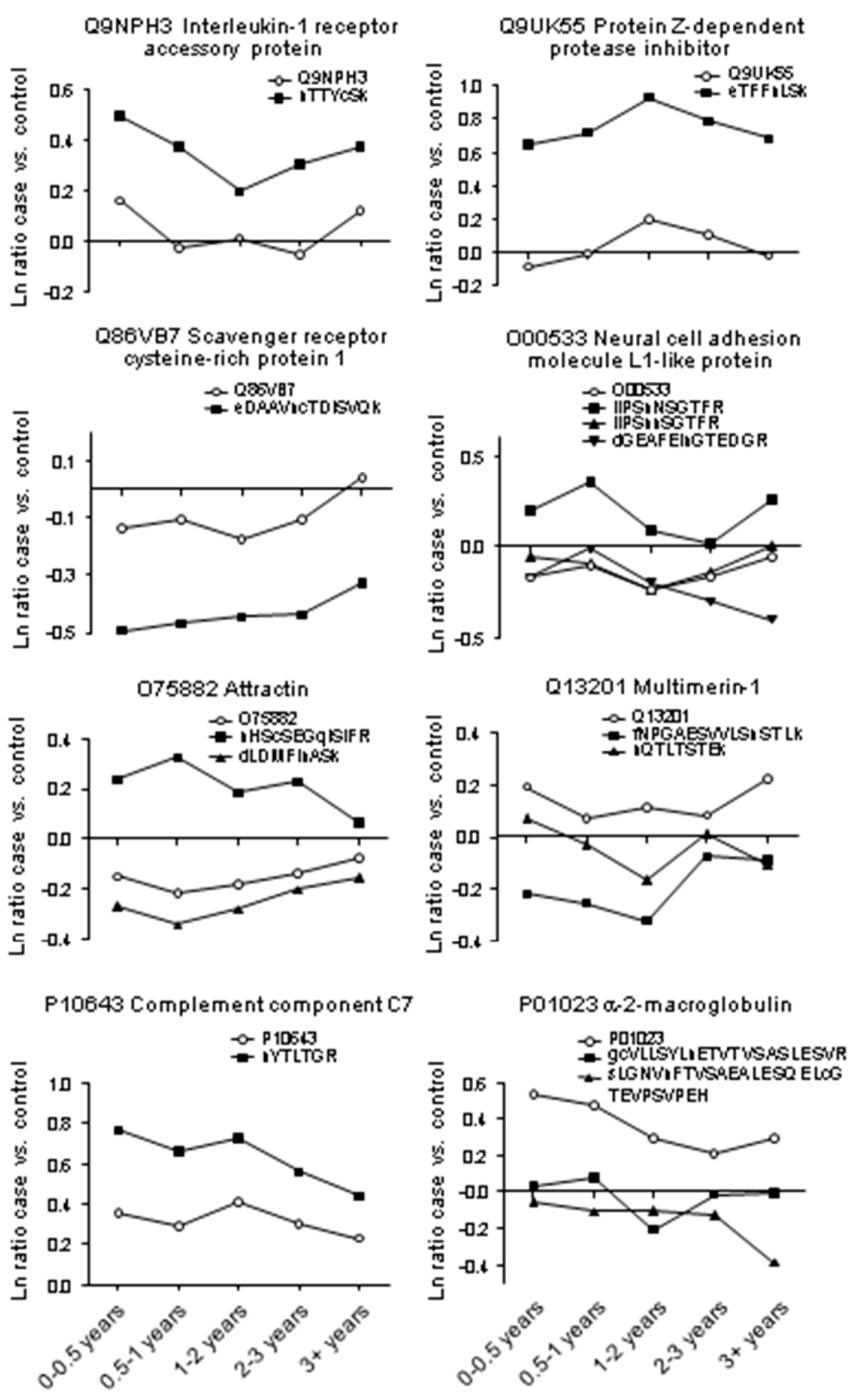

(b)

Figure 2. (a) Examples of altered glycoproteins whose constituent glycopeptides match the pattern of expression of their parent protein; (b) Examples of glycoproteins whose constituent glycopeptides deviate from the pattern of expression of their parent protein. Graphs show the median natural $\log (\ln )$ ratio of case versus control for protein (open circles) at each time group prior to diagnosis of pancreatic cancer. Protein ratios were derived from TMT reporter ion intensity ratios for all peptides matching that protein. Closed symbols show ln ratio for case versus control across time groups for specific glycopeptides matching those proteins. Some examples show the same peptide sequence with different deamidation $(\mathrm{N}$ and $\mathrm{Q})$ modifications.

The most striking differences in protein and glycopeptide profiles were for the four subclasses of the immunoglobulin heavy constant gamma chain (IGHG) isotype. Each possesses a single conserved site of $\mathrm{N}$-glycosylation and generates unique, but highly homologous, tryptic peptides. The IGHG1 protein and glycopeptide profiles were essentially identical, with evidence of elevated expression in cases peaking in the $0.5-1$ year prediagnosis time group (Figure 3 ). Whereas the protein profiles for IGHG2, IGHG3, and IGHG4 were similar to that of IGHG1 (i.e., elevated in cases and peaking in the 0.5-1 year time group), the single glycopeptides identified from IGHG2 and IGHG3 were markedly lower in cases and changed little across the time course. For the IGHG4-derived glycopeptide, levels were reduced compared with the parent protein, but were essentially unchanged between case and control groups. Whilst similar protein profiles may be expected for these proteins as they share a 
significant proportion of the same peptides, unique matching peptides also displayed similarly altered ratios across the time groups (Table S1). Notably, the immunoglobulin isotypes IGHA1, IGHA2, IGHD, IGHM, IGKC, IGLC2, IGLC6, and the immunoglobulin J chain (IGJ) also shared similar profiles to the four IGHG subclasses (Figure 2a; Table S7). This suggests a transient antibody response in the lead-up to diagnosis of pancreatic cancer.
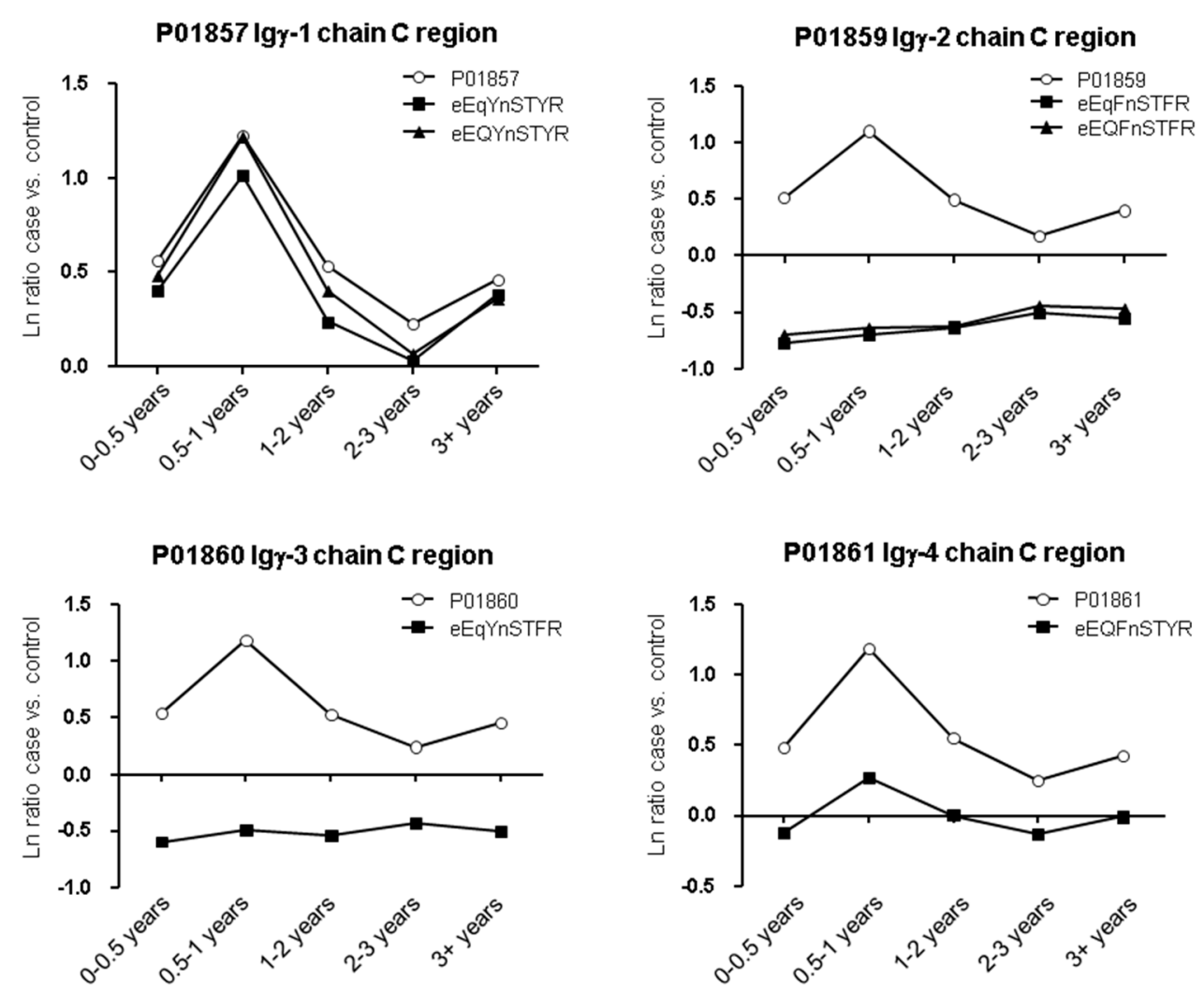

Figure 3. Expression of immunoglobulin G heavy chains and constituent glycopeptides. Graphs show the median natural $\log (\mathrm{ln})$ ratio of case versus control for protein (open circles) at each time group prior to diagnosis of pancreatic cancer. Protein ratios were derived from TMT reporter ion intensity ratios for all peptides matching that protein from analysis of the $\mathrm{TiO}_{2}$ non-bound fractions (Table S6) to mitigate the significant effect that glycopeptide count had on the total protein ratio; IGHG2 glycopeptide counts represented more than half of total peptide counts. Closed symbols show the $\ln$ ratio across time groups for specific matched glycopeptides using reporter ion intensity ratios from the combined analysis.

\subsection{Identification of N-Glycosylation Sites}

Our analysis revealed 426 putative sites of $N$-glycosylation on 167 glycoproteins based on the consensus sequence and deamidation of the asparagine residue (Tables S1 and S4). Mostly, known $\mathrm{N}$-glycosylation sites (reported in SwissProt) were identified, confirming the effectiveness of the strategy. However, we also found evidence of 24 novel sites on 22 proteins (Table S5). For 13 of these potential sites, corresponding non-deamidated peptides were also identified, suggesting either that these sites are not fully $\mathrm{N}$-glycosylated in the serum forms of these proteins or that they are not bona fide sites and are the result of spontaneous chemical deamidation [42]. Examples include C1S-N682, GC-N288, F2-N205, LRG1-N306, F13A1-N19, and ANGPTL3-N23. Putative sites were also identified on several proteins not known to be secreted or not transmembrane domain-containing proteins (ACTB, ACTG1, TPM3, TPM4, FLNA, CA1, PEPD, SDPR, and GTF3C1), and are therefore unlikely to be $N$-glycosylated in vivo and are the result of chemical deamidation. However, sites identified on dopamine $\beta$-hydroxylase (N343), neural cell adhesion molecule L1-like protein (N87), peptidyl-prolyl cis-trans isomerase A (N71), P-selectin (N272), target of nesh-SH3 (N878), and CD34 (N362) appear to 
be novel, but would require further validation. This could be achieved by incorporating ${ }^{18} \mathrm{O}$-labelling at enzymatic deglycosylation and searching for the mass shift in putative glycopeptides, as previously reported [42].

\subsection{Testing $\alpha-1$-Antitrypsin as an Early Biomarker of Pancreatic Cancer}

We wanted to further test our top-scoring "hit" - $\alpha$-1-antitrypsin (A1AT)—as a potential early biomarker of PDAC. Serum A1AT was assayed in 92 individual cases and 120 control samples by ELISA, and levels were compared across time to diagnosis time groups (Figure 4). A1AT serum levels were significantly elevated in cases versus controls for the $0-1$ years $(p=0.003)$ and $1-2$ years $(p=0.046)$ prediagnosis time groups, thus partly validating the findings of the MS-based quantification. The difference between all case and control samples $(0-4+$ years) was also significant $(p=0.045)$. Combining A1AT with serum CA19-9 (the current best biomarker for pancreatic cancer) provided only moderate improvement in area under the curve (AUC) and sensitivity at fixed specificity across the time groups, showing that A1AT does not complement CA19-9 for the detection of pancreatic cancer (Table 3).

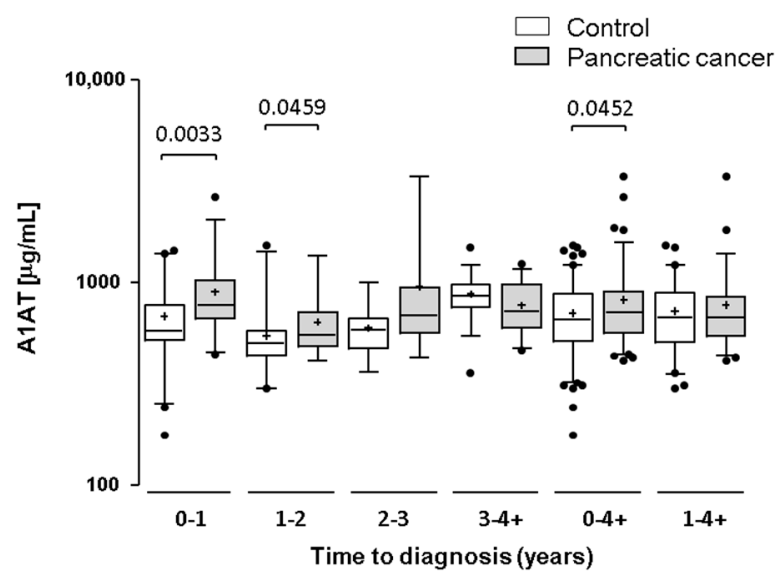

Figure 4. Testing $\alpha$-1-antitrypsin (A1AT) as an early biomarker. Box and whisker plots showing A1AT ELISA data for individual case samples in different time groups prior to PDAC diagnosis and matched controls. Whiskers represent the 5 th and 95th percentiles. The $p$ values are shown for significant $(p<0.05)$ differences.

Table 3. Performance of logistic regression models comparing carbohydrate antigen 19-9 (CA19-9) alone and CA19-9 and A1AT in combination. The number of case samples is shown for each group. Data from all control samples $(n=120)$ was used. The area under the receiver operating characteristics curve (AUC) and sensitivities are shown for both models for each time group at a fixed specificity of 0.95 .

\begin{tabular}{|c|c|c|c|c|}
\hline Time Group & No. Case Samples & Marker Model & AUC & Sensitivity at 0.95 Specificity \\
\hline \multirow{2}{*}{$0-1$ years } & \multirow{2}{*}{34} & CA9-9 & 0.799 & 0.647 \\
\hline & & CA19-9, A1AT & 0.88 & 0.647 \\
\hline \multirow{2}{*}{$1-2$ years } & \multirow{2}{*}{17} & CA9-9 & 0.579 & 0.176 \\
\hline & & CA19-9, A1AT & 0.664 & 0.235 \\
\hline \multirow{2}{*}{$2+$ years } & \multirow{2}{*}{41} & CA9-9 & 0.618 & 0.073 \\
\hline & & CA19-9, A1AT & 0.644 & 0.146 \\
\hline \multirow{2}{*}{$0-2$ years } & \multirow{2}{*}{51} & CA9-9 & 0.726 & 0.49 \\
\hline & & CA19-9, A1AT & 0.76 & 0.471 \\
\hline \multirow{2}{*}{$0-3$ years } & \multirow{2}{*}{64} & CA9-9 & 0.7 & 0.422 \\
\hline & & CA19-9, A1AT & 0.738 & 0.438 \\
\hline \multirow{2}{*}{$0-4+$ years (All) } & \multirow{2}{*}{92} & CA9-9 & 0.678 & 0.304 \\
\hline & & CA19-9, A1AT & 0.709 & 0.315 \\
\hline
\end{tabular}




\section{Discussion}

Using a $\mathrm{TiO}_{2}$-based enrichment strategy linked to quantitative LC-MS/MS by TMT labelling, we have compared serum protein and glycopeptide profiles of noncancer controls with those of women who went on to be diagnosed with PDAC. Numerous changes in the abundances of glycoproteins and glycopeptides were found between case and control groups and across the time groups, identifying them as potential early markers of PDAC and its progression. Notably, we provide evidence that some sites of glycosylation are altered in PDAC and detectable prior to clinical diagnosis and that this is either due to changes in site occupancy or sialic acid content. Conversely, several high-scoring, abundant, and known inflammatory glycoproteins were identified whose glycopeptide and protein profiles matched closely, suggesting minimal changes in their glycosylation in the presence of cancer. This highlights the importance of investigating glycoprotein and glycopeptide levels in parallel across the same set of samples.

Several previous studies have reported serum glycan profiling of pancreatic case and control groups. Kontro et al. used lectin affinity chromatography to enrich $\alpha-2,6$ sialylated tryptic $\mathrm{N}$-glycopeptides from albumin-depleted sera, comparing relative abundances between pancreatic cancer, acute pancreatitis, and healthy groups by label-free LC-MS/MS [43]. Seventeen mainly acute-phase proteins and immunoglobulins with $27 \mathrm{~N}$-glycosylation sites and 62 glycoforms were identified, with site-specific changes of glycoforms reported between the groups. Notably, this included down-regulation of glycopeptides derived from the IGHG subclasses in the cancer versus control groups, as suggested herein. Another study using a specific anti-sialyl Lewis $\mathrm{X}$ antibody and $\mathrm{N}$-glycan sequencing suggested increased $\mathrm{N}$-glycan branching and increased sialyl Lewis $\mathrm{X}$ content on several acute-phase proteins [29]. This was proposed to be associated with an inflammatory response, being observable in both the PDAC and pancreatitis groups, whereas an increase in core fucosylation appeared to be cancer-specific. Our work supports these previous findings, but additionally suggests that some of the changes reported arise due to altered protein expression, rather than altered glycosylation or site occupancy per se.

We confirmed the up-regulation of our top-scoring glycoprotein A1AT in individual samples by ELISA, observing rising levels in the lead-up to diagnosis. However, whilst A1AT alone performed reasonably well for discriminating prediagnosis pancreatic cancer cases from non-cancer controls, it failed to complement CA19-9 in a combined logistic regression model and, as such, would not be worth pursuing as a useful biomarker for early detection of pancreatic cancer. A1AT is a known acute-phase inflammatory protein elevated in many conditions, including malignancy. As such, it is unlikely to be specific for detecting PDAC, and this may explain its lack of complementarity with CA19-9. Several other acute-phase response proteins were also elevated towards diagnosis (e.g., HP, ORM1, ORM2, CRP, SERPINF2), presumably due to a host systemic inflammatory response- a known prognostic indicator in cancer patients. However, several other known acute-phase reactants were found not to be elevated (e.g., AHSG, SERPINA3, ITIH4, FN, F2, F8, SAP, and CD163), arguing that there may be some specificity in the inflammatory response to pancreatic cancer. The elevated levels of multiple immunoglobulin isotypes observed in PDAC cases may also be relevant in this context. All isotypes showed a peak in abundance in the $0.5-1$ years' time group which then declined closer to diagnosis, although levels remained higher in the cases versus the control group. Whilst not classical acute-phase proteins, these immunoglobulin profiles may indicate an adaptive response to the presence and/or spread of the tumour in PDAC patients.

It is important to note that several of the altered abundant glycoproteins identified had been targeted for immunodepletion as part of the workflow to increase coverage, and, thus, their quantification is likely to be less robust. However, every effort was made to ensure equivalent immunodepletion across the sample groups (average yield was $5.1 \% \pm 0.67 \% ; \mathrm{CV}=13 \%$ ). Also, given the magnitude and different dynamics of the changes observed for these glycoproteins (A1AT, A2M, HP, IGHA, IGHG, IGHM, ORM1, and TF), we conclude that immunodepletion has not caused a significant issue with the quantification of these proteins. 
In terms of altered glycopeptide profiles, the glycopeptides derived from IGHG2, IGHG3, and IGHG4 displayed the most prominent differences to their parent protein profiles, and were strongly indicative of altered glycosylation at these known sites. Most importantly, markedly lower levels of the IGHG2- and IGHG3-derived glycopeptides (IGHG2-N176 and IGHG3-N227) were apparent in the case versus control groups, and changed little towards diagnosis. This indicates a loss of glycosylation and/or reduced sialic acid content at these sites as an early response to PDAC. In support of this, Chen et al. have reported truncation of the IGHG2-N176 glycan in serum from chronic pancreatitis patients, and more so, from PDAC patients [44]. Changes in IgG glycans have also been reported in other cancer types where increased levels of core fucosylated, agalactosyl biantennary glycans were reported [45-48]. Immunoglobulin-associated glycans provide recognition epitopes that engage with lectins to elicit effector functions. Indeed, it is known that agalactosyl glycans on IgGs can act as ligands for mannose-binding protein $\mathrm{C}$ to promote complement activation, clearance of immune complexes, and a pro-inflammatory response [49]. It is tempting to speculate that the changes observed herein may affect these processes in response to the presence of PDAC.

In summary, we have profiled numerous serum protein glycosylation sites and compared glycopeptide levels with their parent proteins in a unique set of serum samples predating diagnosis of PDAC. Importantly, we provide evidence of early alteration of $N$-glycosylation of several serum proteins prior to cancer diagnosis. From our current investigation we cannot say if the IgG glycan changes observed are PDAC-specific or the result of a general inflammatory response. However, the changes occur long before clinical presentation of the disease and, as such, may hold promise as early diagnostic biomarkers. One limitation of our study is that samples from only women were used, being sourced from a screening trial of ovarian cancer. Thus, it may be that the observed changes may not be representative and further work should examine samples from both genders. Another weakness of our study is that pools of samples were investigated, so future work should involve the development of higher throughput assays to specifically measure the IGHG-derived glycopeptides in individual prediagnosis samples. A miniaturised version of the same protocol as described herein could be used, possibly including enrichment of the IgG pool, and using targeted MS/MS to measure the glycopeptides of interest and site occupancy. The utility of these glycopeptides as early detection biomarkers for PDAC could then be formally tested as well as any correlation to clinical pathological features. The work should then be extended to include samples from other cancer types and relevant benign conditions (such as pancreatitis and biliary obstruction), such that specificity and association with inflammation can be appropriately addressed.

\section{Materials and Methods}

\subsection{Ethics and Sample Set}

Serum samples used in this study were obtained from a repository collected as part of the UKCTOCS—a randomised controlled trial of ovarian cancer screening in $\sim 202,000$ postmenopausal women that has assessed the impact of screening on mortality [41]. This nested case control study within UKCTOCS was approved on 12th September 2008 by the Joint UCL/UCLH Research Ethics Committee A (Ref. number 05/Q0505/57). Written informed consent was obtained from donors and no data allowing identification of patients was provided. Women who were subsequently diagnosed with pancreatic ductal adenocarcinoma (cases) were identified by cross-referencing with the Health and Social Care Information Centre cancer registry codes and death codes (ICD10 C25.0/1/2/3/9). Confirmation of diagnosis was also obtained from the Hospitals Episode Statistics database and patient physicians through postal questionnaire. There were a total of 261 serum samples from 154 women who went on to be diagnosed with advanced PDAC after sample collection (mean time to diagnosis of 25.5 months). Controls with no cancer registry code from individual women (1 per case sample) were matched to cases based on collection date and center to minimise variation due to handling. Study set characteristics are presented in Table 4. A subset of these samples were used for pooling into 
five groups according to time-to-diagnosis: $0-0.5$ years, $n=20$; $0.5-1$ years, $n=20$; $1-2$ years, $n=20$; $2-3$ years, $n=20$; $3+$ years, $n=40$; and a pool of the corresponding matched non-cancer controls, $n=100$, as reported previously [50].

Table 4. Study set characteristics.

\begin{tabular}{cccc}
\hline Variable & Cases & Controls & $p$ Value \\
\hline No. individuals & 154 & 304 & - \\
No. samples & 261 & 304 & - \\
\hline Tumour site & & & \\
Tail & 8 & na & - \\
Body & 10 & na & - \\
Head & 65 & na & - \\
Unspecified & 71 & na & - \\
Mean time to spin (h) (range) & $21.8(0.5-47)$ & $22.0(6.9-47)$ & 0.62 \\
Mean age at sample draw (years) (range) & $64.64(51.6-74.4)$ & $62.67(50.6-77.5)$ & 0.049 \\
Mean BMI (kg/m (range) $^{2}$ (rang $)$ & $27.1(18.6-42.7)$ & $26.7(17.9-44.4)$ & 0.446 \\
Mean time from sample collection to diagnosis (months) (range) & $25.5(0-79)$ & na & - \\
\hline
\end{tabular}

BMI, Body Mass Index; na, not applicable.

\subsection{Serum Immunodepletion}

Each of the six sample pools were immunodepleted using Proteome Purify 12 Human Serum Protein Immunodepletion Resin (R\&D Systems, Minneapolis, MN, USA; \#IDR012). Briefly, $45 \mu \mathrm{L}$ of serum pool was incubated with $4.5 \mathrm{~mL}$ of immunodepletion resin for $45 \mathrm{~min}$ on a rotator at $4{ }^{\circ} \mathrm{C}$ in polypropylene columns (Thermo Scientific Pierce, Waltham, MA, USA; \#PI29924). Following incubation, the depleted serum was collected and concentrated to $500 \mu \mathrm{L}$ using $5 \mathrm{kDa}$ molecular weight cut-off Vivaspin columns (Sartorius, Tagelswangen, Switzerland; \#VS04T11). Samples were vacuum dried and resuspended in a buffer consisting of $100 \mathrm{mM}$ triethylammonium bicarbonate (TEAB) and $0.1 \%$ SDS, and the protein content was determined using the Coomassie Plus Assay Kit (Thermo Scientific Pierce, Waltham, MA, USA; \#90064). A quantity of $100 \mu \mathrm{g}$ of protein from each pool at $1 \mu \mathrm{g} / \mu \mathrm{L}$ was taken for tryptic digestion followed by TMT labelling.

\subsection{Digestion, Tandem Mass Tag Labelling, and Sample Clean-Up}

Depleted serum pools were reduced with $1 \mathrm{mM}$ tris(2-carboxyethyl)phosphine (TCEP) for $1 \mathrm{~h}$ at $55{ }^{\circ} \mathrm{C}$ with shaking at $600 \mathrm{rpm}$, followed by alkylation with iodoacetamide $(7.5 \mathrm{mM}$ final concentration) for $1 \mathrm{~h}$ at room temperature in the dark, and then digested in solution with $4 \mu \mathrm{g}$ of proteomics-grade modified trypsin (Sigma-Aldrich, Dorset, UK; \#T6567) overnight at $37^{\circ} \mathrm{C}$ with mild shaking. The TMTsixplex ${ }^{\mathrm{TM}}$ isobaric label reagent set (Thermo Scientific, Waltham, MA, USA; \#90061) was used to label each of the sample pools: 0-0.5 years, 0.5-1 year, 1-2 years, 2-3 years, 3+ years, and control pool were labelled with TMT reagents 126, 127, 128, 129, 130, and 131, respectively. Briefly, $0.8 \mathrm{mg}$ of each labelling reagent was resuspended in $41 \mu \mathrm{L}$ acetonitrile and added to the digested samples; samples were vortexed gently, centrifuged, and incubated for $1 \mathrm{~h}$ at room temperature. Reactions were quenched by adding hydroxylamine to a final concentration of $0.25 \%$ and the mixtures were incubated for $30 \mathrm{~min}$ at room temperature. All six samples were then combined. Detergent removal spin columns (Pierce, Waltham, MA, USA; \#87777) were used to remove SDS from the sample mixture following the manufacturer's protocol. Briefly, spin columns were centrifuged for $1 \mathrm{~min}$ at $1500 \times g$ to remove the storage buffer, followed by addition of $400 \mu \mathrm{L}$ equilibration buffer (100 $\mathrm{mM}$ TEAB pH 8.0) and centrifugation at $1500 \times g$ for $1 \mathrm{~min}$ with the flow-through discarded. This step was repeated thrice. Samples were added ( $100 \mu \mathrm{L}$ to each column) and incubated for $2 \mathrm{~min}$ at room temperature before centrifugation into fresh lo-bind Eppendorf tubes (Sigma-Aldrich, Dorset, UK). Samples were dried down in a Speed-Vac and resuspended in $2 \%$ phosphoric acid before desalting using Oasis ${ }^{\circledR}$ HLB 1 cc Vac cartridges (Waters, Milford, MA, USA; \#186000383) according 
to the manufacturer's protocol, eluting with $2 \mathrm{~mL}$ acetonitrile (ACN). Samples were then dried to completeness using a SpeedVac (Thermo Scientific, Waltham, MA, USA).

\subsection{Titanium Oxide $\left(\mathrm{TiO}_{2}\right)$ Enrichment}

Peptides were resuspended in $100 \mu \mathrm{L}$ loading buffer $(80 \%$ ACN, $5 \%$ trifluoroacetic acid (TFA), and $1 \mathrm{M}$ glycolic acid). A quantity of $3 \mathrm{mg}$ of $\mathrm{TiO}_{2}$ beads $(50 \mathrm{mg} / \mathrm{mL}$ in $\mathrm{ACN}$ of $5 \mu \mathrm{m}$ Titansphere beads; GL Sciences, Tokyo, Japan) was added to the $600 \mu \mathrm{g}$ peptide solution and the mixture was incubated on a shaker (1200 rpm) at room temperature for $30 \mathrm{~min}$. Beads were pelleted by centrifugation and the supernatants were carefully collected and re-incubated as above using $3 \mathrm{mg}$ of fresh $\mathrm{TiO}_{2}$ beads. The supernatants containing unbound peptides from both incubation steps were mixed together and further fractionated by high $\mathrm{pH}$ reversed-phase liquid chromatography (see below). The $\mathrm{TiO}_{2}$ beads with bound peptides were mixed together and washed with $80 \mu \mathrm{L}$ loading buffer for $15 \mathrm{~s}$, then centrifuged to pellet the beads. Beads were washed twice with $80 \mu \mathrm{L}$ of wash buffer $1(80 \% \mathrm{ACN}$ in $1 \%$ TFA), followed by wash buffer $2\left(20 \%\right.$ ACN, $0.1 \%$ TFA). Peptides bound to the $\mathrm{TiO}_{2}$ beads were then eluted in $60 \mu \mathrm{L}$ elution buffer $(1.8 \%$ ammonia in water, $\mathrm{pH} 11.3)$ by mixing and incubation for $10 \mathrm{~min}$ in a thermomixer at room temperature. Samples were then centrifuged for $2 \mathrm{~min}$ and the supernatant was recovered without transfer of beads; samples were then evaporated to dryness in a SpeedVac. Samples were resuspended in $50 \mu \mathrm{L}$ of $50 \mathrm{mM} \mathrm{TEAB} \mathrm{(pH} \mathrm{8.0)} \mathrm{and} \mathrm{deglycosylated} \mathrm{with} 500 \mathrm{U}$ of PNGase F (Roche, Basel, Switzerland) at $37^{\circ} \mathrm{C}$ overnight. Trifluoroacetic acid was added to $0.5 \%$ final concentration and the samples were subjected to clean-up using C18 Zip tips.

\subsection{Strong Cation Exchange (SCX) and High $p H$ RP-LC Fractionation}

Strong cation exchange (SCX) was performed on the formerly $N$-glycosylated peptides using in-house prepared stage tips to increase coverage by subsequent LC-MS/MS analysis. Briefly, $200 \mu \mathrm{L}$ micropipette tips were used to prepare stage tips with two layers of strong cation exchange resin stacked one on top of the other. The sample mixture was diluted 20 -fold in Solution $\mathrm{A}(80 \% \mathrm{ACN}$; $0.5 \%$ formic acid). This diluted peptide solution was loaded onto the stage tip after the tip was conditioned in Solution A. After washing the resin with Solution A, stepwise elution of the sample mixture was achieved by sequential addition of $14 \mu \mathrm{L}$ of six different elution solutions of increasing ionic strength, all containing $20 \% \mathrm{ACN}$ and $0.5 \%$ formic acid (except Solution 6, which contained no formic acid): (1) $75 \mathrm{mM}$ ammonium acetate; (2) $100 \mathrm{mM}$ ammonium acetate; (3) $150 \mathrm{mM}$ ammonium acetate; (4) $250 \mathrm{mM}$ ammonium acetate; (5) $350 \mathrm{mM}$ ammonium acetate; and (6) $500 \mathrm{mM}$ ammonium acetate. The eluates were evaporated using a Speed-Vac and resuspended in $8 \mu \mathrm{L}$ of nanoLC Mobile Phase A ( $0.1 \%$ formic acid, $2 \% \mathrm{ACN})$ prior to nanoLC-MS/MS analysis. To improve the coverage of the $\mathrm{TiO}_{2}$-unbound fraction (nominally non-glycosylated peptides or low-content sialic acid glycopeptides), fractionation was performed by reversed-phase HPLC at high $\mathrm{pH}$. Briefly, the sample was resuspended in $2 \mathrm{mM}$ ammonium formate at $\mathrm{pH}$ 8.4, loaded onto a reversed-phase column (PoroShell C18; Agilent, Santa Clara, CA, USA), and run on an Agilent 1100 HPLC system. Thirty fractions were collected by eluting with increasing concentrations of $\mathrm{ACN}(3-45 \%)$ over $35 \mathrm{~min}$. Fractions were dried to completion prior to LC-MS/MS analysis.

\subsection{LC-MS/MS Analysis}

All fractions (4 repeats of the unfractionated $\mathrm{TiO}_{2}$-bound material, $6 \mathrm{SCX}$ fractions of the $\mathrm{TiO}_{2}$-bound material, and 30 high pH RP-LC fractions of the unbound material) were analysed using a Thermo QExactive ${ }^{\circledR}$ quadrupole orbitrap mass spectrometer coupled to an Easy LC 1000 nanoscale liquid chromatography system (Thermo Fisher Scientific, Waltham, MA, USA). A $10 \mathrm{~cm}$, in-house pulled, analytical LC column of $75 \mu \mathrm{m}$ i.d. packed with $3 \mu \mathrm{m} \mathrm{C18} \mathrm{silica} \mathrm{particles} \mathrm{(Dr} \mathrm{Maisch,}$ $\mathrm{GmbH}$, Ammerbuch, Germany) was used. Peptide mixtures were directly loaded onto the analytical column at $500 \mathrm{~nL} / \mathrm{min}$ in Mobile Phase A (see above) and eluted at a $300 \mathrm{~nL} / \mathrm{min}$ flow rate with Mobile Phase B ( $0.1 \%$ formic acid, $80 \%$ acetonitrile), increasing from $2 \%$ to $32 \%$ over $60 \mathrm{~min}$, and from $32 \%$ to 
$100 \%$ over an additional $20 \mathrm{~min}$. The column was re-equilibrated to $2 \% \mathrm{~B}$ for $10 \mathrm{~min}$ before successive injection. The mass spectrometer was operated in positive ion mode with a nanospray potential of $1800 \mathrm{~V}$. Acquisition of spectra was performed in a data-dependent manner using a top-ten method, where the ten most abundant ions were automatically selected for HCD fragmentation at a normalised collision energy of $32 \%$. Resolution, automatic gain control target and maximum injection time for full MS were 70,000, $1 \times 10^{6}$, and $50 \mathrm{~ms}$, respectively, and for MS/MS were 35,000, $1 \times 10^{5}$, and $120 \mathrm{ms,}$ respectively. The mass window for precursor ion isolation was $2.0 \mathrm{~m} / \mathrm{z}$ and dynamic exclusion was set for $30 \mathrm{~s}$.

\subsection{Mass spectrometry Data Analysis}

Peptide identification and quantification were performed on the combined dataset by processing the raw data files produced in Xcalibur software v.3.1 (Thermos Scientific, Waltham, MA, USA) using Proteome Discoverer v1.4 (Thermo Scientific, Waltham, MA, USA). Database searching was performed using Mascot v2.4 against the human SwissProt database (20,160 entries; 17 February 2016). Search parameters were: taxonomy human; MS tolerance $\pm 10 \mathrm{ppm} ; \mathrm{MS} / \mathrm{MS}$ tolerance $\pm 0.5 \mathrm{Da}$; one missed cleavage was allowed; carbamidomethylation of cysteines and TMT6plex modification of peptide $\mathrm{N}$-termini and lysine residues were set as fixed modification; methionine oxidation and NQ deamidation $(\mathrm{NQ})$ were set as variable modifications. Protein grouping was enabled and only peptides with a score $>20$ and below the Mascot significance threshold of $p=0.05$ were included in further analysis. Putative glycopeptides were identified based on the presence of the consensus sequence NXS/T (where $X \neq P$ ) with deamidation of the asparagine. Quantitative information was calculated from reporter ion intensities with case time groups compared to the healthy pool (reagent 131). A cumulative scoring system was devised for protein groups and putative glycopeptides taking into account fold-change, consistency and pattern of change across time groups, number of unique peptides (for proteins) or ion score (for peptides), reporter ion counts, and variability. Altered glycosylation was examined by comparing protein ratios derived from TMT reporter ion intensity ratios for all peptides matching that protein (except for IGHG1-4) and compared with ratios for the glycopeptides matching that protein.

\subsection{Serum Assays and Data Analysis}

All serum samples were randomised and blinded to the experimenter for testing. Serum CA19-9 was measured as part of a previous study [14] using the Cobas CA19-9 CLIA with a CA19-9 Calibrator Set, run on a Cobas E411 analyser with PreciControl Tumour Marker to monitor assay imprecision (Roche Diagnostics Burgess Hill, UK). Replicate measurements of a serum standard run at the same time $(n=31)$ yielded an average CV of $3.2 \%$. Serum $\alpha$-1-antitrypsin (A1AT) was measured using the 1 1-Antitrypsin ELISA Kit (Immundiagnostik, Bensheim, Germany) according to the manufacturer's instruction, using a 1:25,000 serum dilution. Replicate readings gave an average CV of 10.7\%. Data was analysed in GraphPad Prism v5 (La Jolla, CA, USA) with significance between cases and controls assessed using the Mann-Whitney $U$ test. The $R$ statistical and graphics environment v3.2.5 (The $R$ Foundation, Vienna, Austria) was used for logistic regression modelling and testing by Receiver Operating Characteristics (ROC) curve analysis, with the area under the ROC curve (AUC) reported.

Supplementary Materials: Supplementary materials can be found at www.mdpi.com/1422-0067/18/12/2670/s1.

Acknowledgments: This research was funded by Pancreatic Cancer UK project grant P53176 (to Stephen P. Pereira and John F. Timms) and POR Calabria FSE 1007-2013 “HEMMAS"(IT) (to Marco Gaspari), and was supported by the National Institute for Health Research (NIHR) University College London Hospitals (UCLH) Biomedical Research Centre. UKCTOCS was core funded by the Medical Research Council (G9901012/G0801228), Cancer Research UK (C1479/A2884) and the Department of Health with additional support from the Eve Appeal, Special Trustees of Bart's and the London, and Special Trustees of UCLH (to Usha Menon).

Author Contributions: Marco Gaspari and John F. Timms conceived and designed the study and secured grant funding. Usha Menon and Aleksandra Gentry-Maharaj provided clinical samples. Shibu Krishnan performed MS-based profiling. Shibu Krishnan, Harry J. Whitwell and John F. Timms performed data analysis and Joy Cuenco 
conducted ELISA assays. Marco Gaspari, Stephen P. Pereira and John F. Timms drafted and edited the manuscript. All authors commented on and approved the final version.

Conflicts of Interest: Usha Menon has a financial interest through UCL Business and Abcodia Ltd. in the third party exploitation of clinical trials biobanks which have been developed through research at UCL. None of the other authors have conflicts of interest.

\section{Abbreviations}

$\begin{array}{ll}\text { ACN } & \text { acetonitrile } \\ \text { AUC } & \text { area under the ROC curve } \\ \text { LC-MS/MS } & \text { liquid chromatography tandem mass spectrometry } \\ \text { PDAC } & \text { pancreatic ductal adenocarcinoma } \\ \text { ROC } & \text { receiver operating characteristics } \\ \text { SCX } & \text { strong cation exchange } \\ \text { TEAB } & \text { triethylammonium bicarbonate } \\ \text { TCEP } & \text { tris(2-carboxyethyl)phosphine } \\ \mathrm{TiO}_{2} & \text { titanium oxide } \\ \text { TMT } & \text { tandem mass tags } \\ \text { TFA } & \text { trifluoroacetic acid } \\ \text { UKCTOCS } & \text { UK Collaborative Trial of Ovarian Cancer Screening }\end{array}$

\section{References}

1. CRUK. Pancreatic Cancer Statistics. Available online: http://www.cancerresearchuk.org/healthprofessional/cancer-statistics/statistics-by-cancer-type/pancreatic-cancer (accessed on 13 November 2017).

2. Siegel, R.; Naishadham, D.; Jemal, A. Cancer statistics, 2013. CA 2013, 63, 11-30. [CrossRef] [PubMed]

3. Baeckstrom, D.; Hansson, G.C.; Nilsson, O.; Johansson, C.; Gendler, S.J.; Lindholm, L. Purification and characterization of a membrane-bound and a secreted mucin-type glycoprotein carrying the carcinoma-associated sialyl-Lea epitope on distinct core proteins. J. Biol. Chem. 1991, 266, 21537-21547. [PubMed]

4. Baeckstrom, D.; Nilsson, O.; Price, M.R.; Lindholm, L.; Hansson, G.C. Discrimination of MUC1 mucins from other sialyl-Le ${ }^{\mathrm{a}}$-carrying glycoproteins produced by colon carcinoma cells using a novel monoclonal antibody. Cancer Res. 1993, 53, 755-761. [PubMed]

5. Ho, J.J.; Siddiki, B.; Kim, Y.S. Association of sialyl-Lewis ${ }^{\mathrm{a}}$ and sialyl-Lewis ${ }^{\mathrm{x}}$ with MUC-1 apomucin ina pancreatic cancer cell line. Cancer Res. 1995, 55, 3659-3663. [PubMed]

6. Ballehaninna, U.K.; Chamberlain, R.S. The clinical utility of serum CA 19-9 in the diagnosis, prognosis and management of pancreatic adenocarcinoma: An evidence based appraisal. J. Gastrointest. Oncol. 2012, 3, 105-119. [PubMed]

7. Duffy, M.J. Carcinoembryonic antigen as a marker for colorectal cancer: Is it clinically useful? Clin. Chem. 2001, 47, 624-630. [PubMed]

8. Lamerz, R. Role of tumour markers, cytogenetics. Ann. Oncol. 1999, 10, 145-149. [CrossRef] [PubMed]

9. Steinberg, W. The clinical utility of the CA 19-9 tumor-associated antigen. Am. J. Gastroenterol. 1990, 85, 350-355. [PubMed]

10. DiMagno, E.P.; Reber, H.A.; Tempero, M.A. AGA technical review on the epidemiology, diagnosis, and treatment of pancreatic ductal adenocarcinoma. American gastroenterological association. Gastroenterology 1999, 117, 1464-1484. [PubMed]

11. Chang, C.Y.; Huang, S.P.; Chiu, H.M.; Lee, Y.C.; Chen, M.F.; Lin, J.T. Low efficacy of serum levels of CA 19-9 in prediction of malignant diseases in asymptomatic population in taiwan. Hepatogastroenterology 2006, 53, 1-4. [PubMed]

12. Kim, J.E.; Lee, K.T.; Lee, J.K.; Paik, S.W.; Rhee, J.C.; Choi, K.W. Clinical usefulness of carbohydrate antigen 19-9 as a screening test for pancreatic cancer in an asymptomatic population. J. Gastroenterol. Hepatol. 2004, 19, 182-186. [CrossRef]

13. Satake, K.; Takeuchi, T.; Homma, T.; Ozaki, H. CA19-9 as a screening and diagnostic tool in symptomatic patients: The Japanese experience. Pancreas 1994, 9, 703-706. [CrossRef] [PubMed] 
14. O’Brien, D.P.; Sandanayake, N.S.; Jenkinson, C.; Gentry-Maharaj, A.; Apostolidou, S.; Fourkala, E.O.; Camuzeaux, S.; Blyuss, O.; Gunu, R.; Dawnay, A.; et al. Serum CA19-9 is significantly up-regulated up to 2 years prior to diagnosis with pancreatic cancer: Implications for early disease detection. Clin. Cancer Res. 2015, 21, 622-631. [CrossRef] [PubMed]

15. Cwik, G.; Wallner, G.; Skoczylas, T.; Ciechanski, A.; Zinkiewicz, K. Cancer antigens 19-9 and 125 in the differential diagnosis of pancreatic mass lesions. Arch. Surg. 2006, 141, 968-973. [CrossRef]

16. Haga, Y.; Sakamoto, K.; Egami, H.; Yoshimura, R.; Mori, K.; Akagi, M. Clinical significance of serum CA125 values in patients with cancers of the digestive system. Am. J. Med. Sci. 1986, 292, 30-34. [CrossRef] [PubMed]

17. Haglund, C. Tumour marker antigen CA125 in pancreatic cancer: A comparison with CA19-9 and CEA. Br. J. Cancer 1986, 54, 897-901. [CrossRef] [PubMed]

18. Sakamoto, K.; Haga, Y.; Yoshimura, R.; Egami, H.; Yokoyama, Y.; Akagi, M. Comparative effectiveness of the tumour diagnostics, CA 19-9, CA 125 and carcinoembryonic antigen in patients with diseases of the digestive system. Gut 1987, 28, 323-329. [CrossRef] [PubMed]

19. Yasue, M.; Sakamoto, J.; Teramukai, S.; Morimoto, T.; Yasui, K.; Kuno, N.; Kurimoto, K.; Ohashi, Y. Prognostic values of preoperative and postoperative CEA and CA19.9 levels in pancreatic cancer. Pancreas 1994, 9, 735-740. [CrossRef] [PubMed]

20. Simeone, D.M.; Ji, B.; Banerjee, M.; Arumugam, T.; Li, D.; Anderson, M.A.; Bamberger, A.M.; Greenson, J.; Brand, R.E.; Ramachandran, V.; et al. CEACAM1, a novel serum biomarker for pancreatic cancer. Pancreas 2007, 34, 436-443. [CrossRef] [PubMed]

21. Gold, D.V.; Modrak, D.E.; Ying, Z.; Cardillo, T.M.; Sharkey, R.M.; Goldenberg, D.M. New MUC1 serum immunoassay differentiates pancreatic cancer from pancreatitis. J. Clin. Oncol. 2006, 24, 252-258. [CrossRef] [PubMed]

22. Koopmann, J.; Fedarko, N.S.; Jain, A.; Maitra, A.; Iacobuzio-Donahue, C.; Rahman, A.; Hruban, R.H.; Yeo, C.J.; Goggins, M. Evaluation of osteopontin as biomarker for pancreatic adenocarcinoma. Cancer Epidemiol. Biomark. Prev. 2004, 13, 487-491. [CrossRef]

23. Koopmann, J.; Buckhaults, P.; Brown, D.A.; Zahurak, M.L.; Sato, N.; Fukushima, N.; Sokoll, L.J.; Chan, D.W.; Yeo, C.J.; Hruban, R.H.; et al. Serum macrophage inhibitory cytokine 1 as a marker of pancreatic and other periampullary cancers. Clin. Cancer Res. 2004, 10, 2386-2392. [CrossRef]

24. Faca, V.M.; Song, K.S.; Wang, H.; Zhang, Q.; Krasnoselsky, A.L.; Newcomb, L.F.; Plentz, R.R.; Gurumurthy, S.; Redston, M.S.; Pitteri, S.J.; et al. A mouse to human search for plasma proteome changes associated with pancreatic tumor development. PLoS Med. 2008, 5, e123.

25. Rosty, C.; Christa, L.; Kuzdzal, S.; Baldwin, W.M.; Zahurak, M.L.; Carnot, F.; Chan, D.W.; Canto, M.; Lillemoe, K.D.; Cameron, J.L.; et al. Identification of hepatocarcinoma intestine pancreas/pancreatitis associated protein 1 as a biomarker for pancreatic ductal adenocarcinoma by protein biochip technology. Cancer Res. 2002, 62, 1868-1875.

26. Cerwenka, H.; Aigner, R.; Bacher, H.; Werkgartner, G.; el-Shabrawi, A.; Quehenberger, F.; Mischinger, H.J. TUM2-PK (pyruvate kinase type tumor M2), CA19-9 and CEA in patients with benign, malignant and metastasizing pancreatic lesions. Anticancer Res. 1999, 19, 849-851.

27. Rudd, P.M.; Dwek, R.A. Glycosylation: Heterogeneity and the 3D structure of proteins. Crit. Rev. Biochem. Mol. Biol. 1997, 32, 1-100.

28. Zhao, J.; Qiu, W.; Simeone, D.M.; Lubman, D.M. N-linked glycosylation profiling of pancreatic cancer serum using capillary liquid phase separation coupled with mass spectrometric analysis. J. Proteome Res. 2007, 6, 1126-1138. [CrossRef]

29. Sarrats, A.; Saldova, R.; Pla, E.; Fort, E.; Harvey, D.J.; Struwe, W.B.; de Llorens, R.; Rudd, P.M.; Peracaula, R. Glycosylation of liver acute-phase proteins in pancreatic cancer and chronic pancreatitis. Proteom. Clin. Appl. 2010, 4, 432-448. [CrossRef]

30. Terao, N.; Takamatsu, S.; Minehira, T.; Sobajima, T.; Nakayama, K.; Kamada, Y.; Miyoshi, E. Fucosylation is a common glycosylation type in pancreatic cancer stem cell-like phenotypes. World J. Gastroenterol. 2015, 21, 3876-3887. [CrossRef]

31. Pan, S.; Brentnall, T.A.; Chen, R. Glycoproteins and glycoproteomics in pancreatic cancer. World J. Gastroenterol. 2016, 22, 9288-9299. [CrossRef] 
32. Pan, S.; Chen, R.; Tamura, Y.; Crispin, D.A.; Lai, L.A.; May, D.H.; McIntosh, M.W.; Goodlett, D.R.; Brentnall, T.A. Quantitative glycoproteomics analysis reveals changes in N-glycosylation level associated with pancreatic ductal adenocarcinoma. J. Proteome Res. 2014, 13, 1293-1306. [CrossRef]

33. Lau, K.S.; Dennis, J.W. N-glycans in cancer progression. Glycobiology 2008, 18, 750-760. [CrossRef]

34. Dimitroff, C.J. Galectin-binding O-glycosylations as regulators of malignancy. Cancer Res. 2015, 75, 3195-3202. [CrossRef]

35. Chia, J.; Goh, G.; Bard, F. Short O-galnac glycans: Regulation and role in tumor development and clinical perspectives. Biochim. Biophys. Acta 2016, 1860, 1623-1639. [CrossRef]

36. Fry, S.A.; Afrough, B.; Lomax-Browne, H.J.; Timms, J.F.; Velentzis, L.S.; Leathem, A.J. Lectin microarray profiling of metastatic breast cancers. Glycobiology 2011, 21, 1060-1070. [CrossRef]

37. Drake, R.R.; Schwegler, E.E.; Malik, G.; Diaz, J.; Block, T.; Mehta, A.; Semmes, O.J. Lectin capture strategies combined with mass spectrometry for the discovery of serum glycoprotein biomarkers. Mol. Cell. Proteom. 2006, 5, 1957-1967. [CrossRef]

38. Larsen, M.R.; Jensen, S.S.; Jakobsen, L.A.; Heegaard, N.H. Exploring the sialiome using titanium dioxide chromatography and mass spectrometry. Mol. Cell. Proteom. 2007, 6, 1778-1787. [CrossRef]

39. Zhang, H.; Li, X.J.; Martin, D.B.; Aebersold, R. Identification and quantification of N-linked glycoproteins using hydrazide chemistry, stable isotope labeling and mass spectrometry. Nat. Biotechnol. 2003, 21, 660-666. [CrossRef]

40. Menon, U.; Gentry-Maharaj, A.; Hallett, R.; Ryan, A.; Burnell, M.; Sharma, A.; Lewis, S.; Davies, S.; Philpott, S.; Lopes, A.; et al. Sensitivity and specificity of multimodal and ultrasound screening for ovarian cancer, and stage distribution of detected cancers: Results of the prevalence screen of the UK Collaborative Trial of Ovarian Cancer Screening (UKCTOCS). Lancet Oncol. 2009, 10, 327-340. [CrossRef]

41. Jacobs, I.J.; Menon, U.; Ryan, A.; Gentry-Maharaj, A.; Burnell, M.; Kalsi, J.K.; Amso, N.N.; Apostolidou, S.; Benjamin, E.; Cruickshank, D.; et al. Ovarian cancer screening and mortality in the UK Collaborative Trial of Ovarian Cancer Screening (UKCTOCS): A randomised controlled trial. Lancet 2016, 387, 945-956. [CrossRef]

42. Palmisano, G.; Melo-Braga, M.N.; Engholm-Keller, K.; Parker, B.L.; Larsen, M.R. Chemical deamidation: A common pitfall in large-scale N-linked glycoproteomic mass spectrometry-based analyses. J. Proteome Res. 2012, 11, 1949-1957. [CrossRef] [PubMed]

43. Kontro, H.; Joenvaara, S.; Haglund, C.; Renkonen, R. Comparison of sialylated N-glycopeptide levels in serum of pancreatic cancer patients, acute pancreatitis patients, and healthy controls. Proteomics 2014, 14, 1713-1723.

44. Chen, A.; Kozak, D.; Battersby, B.J.; Forrest, R.M.; Scholler, N.; Urban, N.; Trau, M. Antifouling surface layers for improved signal-to-noise of particle-based immunoassays. Langmuir 2009, 25, 13510-13515. [CrossRef] [PubMed]

45. Kanoh, Y.; Mashiko, T.; Danbara, M.; Takayama, Y.; Ohtani, S.; Egawa, S.; Baba, S.; Akahoshi, T. Changes in serum IgG oligosaccharide chains with prostate cancer progression. Anticancer Res. 2004, 24, 3135-3139. [PubMed]

46. Kodar, K.; Izotova, J.; Klaamas, K.; Sergeyev, B.; Jarvekulg, L.; Kurtenkov, O. Aberrant glycosylation of the anti-Thomsen-Friedenreich glycotope immunoglobulin $\mathrm{G}$ in gastric cancer patients. World J. Gastroenterol. 2013, 19, 3573-3582. [PubMed]

47. Bones, J.; Byrne, J.C.; O'Donoghue, N.; McManus, C.; Scaife, C.; Boissin, H.; Nastase, A.; Rudd, P.M. Glycomic and glycoproteomic analysis of serum from patients with stomach cancer reveals potential markers arising from host defense response mechanisms. J. Proteome Res. 2011, 10, 1246-1265. [PubMed]

48. Saldova, R.; Royle, L.; Radcliffe, C.M.; Abd Hamid, U.M.; Evans, R.; Arnold, J.N.; Banks, R.E.; Hutson, R.; Harvey, D.J.; Antrobus, R.; et al. Ovarian cancer is associated with changes in glycosylation in both acute-phase proteins and igg. Glycobiology 2007, 17, 1344-1356. [PubMed]

49. Arnold, J.N.; Dwek, R.A.; Rudd, P.M.; Sim, R.B. Mannan binding lectin and its interaction with immunoglobulins in health and in disease. Immunol. Lett. 2006, 106, 103-110. [PubMed]

50. Sinclair, J.; Timms, J.F. Quantitative profiling of serum samples using tmt protein labelling, fractionation and LC-MS/MS. Methods 2011, 54, 361-369. [PubMed]

(C) 2017 by the authors. Licensee MDPI, Basel, Switzerland. This article is an open access article distributed under the terms and conditions of the Creative Commons Attribution (CC BY) license (http://creativecommons.org/licenses/by/4.0/). 